\title{
Variation in the diversity and richness of parasitoid wasps based on sampling effort
}

\author{
Thomas E Saunders ${ }^{1}$, Darren F Ward ${ }^{\text {Corresp. } 1,2}$ \\ ${ }^{1}$ School of Biological Sciences, University of Auckland, Auckland, New Zealand \\ 2 Landcare Research, Auckland, New Zealand \\ Corresponding Author: Darren F Ward \\ Email address: wardda@landcareresearch.co.nz
}

Parasitoid wasps are a mega-diverse, ecologically dominant, but poorly studied component of global biodiversity. In order to maximise the efficiency and reduce the cost of their collection, the application of optimal sampling techniques is necessary. Two sites in Auckland, New Zealand were sampled intensively to determine the relationship between sampling effort and observed species richness of parasitoid wasps from the family Ichneumonidae. Twenty traps were deployed at each site at three different times over the austral summer period, resulting in a total sampling effort of 840 Malaise-trap-days. Rarefaction techniques and non-parametric estimators were used to predict species richness and to evaluate the variation and completeness of sampling. Despite an intensive Malaise-trapping regime over the summer period, no asymptote of species richness was reached. At best, sampling captured two-thirds of parasitoid wasp species present. The estimated total number of species present depended on the month of sampling and the statistical estimator used. Consequently, the use of fewer traps would have caught only a small proportion of all species (one trap 7-21\%; two traps 13-32\%), and many traps contributed little to the overall number of individuals caught. However, variation in the catch of individual Malaise traps was not explained by seasonal turnover of species, vegetation or environmental conditions surrounding the trap, or distance of traps to one another. Overall the results demonstrate that even with an intense sampling effort the community is incompletely sampled. The use of only a few traps and/or for very short periods severely limits the estimates of richness because i) fewer individuals are caught leading to a greater number of singletons; and ii) the considerable variation of individual traps means some traps will contribute few or no individuals. Understanding how sampling effort affects the richness and diversity of parasitoid wasps is a useful foundation for future studies. 
1 Variation in the diversity and richness of parasitoid wasps based on sampling effort

2

3

4

5 Thomas E. Saunders ${ }^{1}$ \& Darren F. Ward ${ }^{1,2}$

6

7

8

$9{ }^{1}$ School of Biological Sciences, University of Auckland, PB 92019, Auckland, New Zealand $10{ }^{2}$ Landcare Research, PB 92170, Auckland, New Zealand

13

14 Corresponding Author:

15 Darren Ward

16 wardda@1andcareresearch.co.nz

17 


\begin{abstract}
Parasitoid wasps are a mega-diverse, ecologically dominant, but poorly studied component of global biodiversity. In order to maximise the efficiency and reduce the cost of their collection, the application of optimal sampling techniques is necessary.

Two sites in Auckland, New Zealand were sampled intensively to determine the relationship between sampling effort and observed species richness of parasitoid wasps from the family Ichneumonidae. Twenty traps were deployed at each site at three different times over the austral summer period, resulting in a total sampling effort of 840 Malaise-trap-days. Rarefaction techniques and non-parametric estimators were used to predict species richness and to evaluate the variation and completeness of sampling.

Despite an intensive Malaise-trapping regime over the summer period, no asymptote of species richness was reached. At best, sampling captured two-thirds of parasitoid wasp species present. The estimated total number of species present depended on the month of sampling and the statistical estimator used. Consequently, the use of fewer traps would have caught only a small proportion of all species (one trap 7-21\%; two traps 13-32\%), and many traps contributed little to the overall number of individuals caught. However, variation in the catch of individual Malaise traps was not explained by seasonal turnover of species, vegetation or environmental conditions surrounding the trap, or distance of traps to one another.

Overall the results demonstrate that even with an intense sampling effort the community is incompletely sampled. The use of only a few traps and/or for very short periods severely limits the estimates of richness because i) fewer individuals are caught leading to a greater number of singletons; and ii) the considerable variation of individual traps means some traps will contribute few or no individuals. Understanding how sampling effort affects the richness and diversity of parasitoid wasps is a useful foundation for future studies.
\end{abstract}


48

49

50

51

52

53

54

55

56

57

58

59

60

61

62

63

64

65

66

67

68

69

70

71

72

73

74

75

76

77

78

79

80

81

82

83

84

85

86

87

88

89

90

91

92

93

\section{Introduction}

Invertebrates comprise the vast majority of global species richness, drive wide-ranging ecological processes, and provide ecosystem services essential for human prosperity (Mora et al., 2011; Chapin III et al., 2000; Potts et al., 2010). Despite their obvious importance, there are numerous impediments to a wider appreciation of their diversity, ecology, and taxonomy (Sluys, 2013; Wheeler et al., 2012). A key barrier is the lack of accurate, standardised, and cost-effective sampling regimes to optimise the collection of species (New 1998; Keating et al., 1998). Consequently, insects are commonly overlooked in conservation planning and assessment chiefly because obtaining even a basic understanding of their taxonomic and functional diversity is often difficult (New 2009; Samways 2005, Holwell \& Andrew 2014).

Parasitoid wasps are solitary insects whose larvae eventually kill the arthropod hosts they feed on during development (Eggleton \& Gaston, 1990). Their total global diversity is estimated at over 350,000 species (Gaston, 1991), making them 7x more diverse than vertebrates. Parasitoid wasps are known to exert considerable influence over ecological processes in both natural and humanmodified environments by regulating their host populations (LaSalle \& Gauld, 1993). For example, parasitoids have repeatedly demonstrated their economic value to humans as biological control agents that significantly reduce the damage and economic losses caused by insect pests in agroecosystems (Van Driesche et al., 2010; LaSalle \& Gauld, 1993). However, parasitoids can also be highly prone to extinction because of their reliance on hosts in lower trophic levels (Shaw \& Hochberg, 2001).

Despite their ecological and economic significance, parasitoid wasps (and Hymenoptera in general) are disproportionately under-represented in insect conservation (Shaw \& Hochberg, 2001; Ward et al. 2012). One of the best ways to include invertebrates in conservation assessment is to gain a better understanding of their distributions and diversity by comparing and evaluating a range of sampling regimes (New, 2012; Southwood \& Henderson, 2000). Ultimately a cost-effective sampling program that returns an accurate inventory of species richness needs to: (i) capture the largest number of individuals in the least amount of time, (ii) predict how the number, spacing, and timing of trap deployments (sampling effort) affects observed species richness, and (iii) measure the completeness of samples collected to decide whether further sampling is worth the effort (New, 1998). This approach to surveying is termed 'optimal sampling', and despite being well developed for marine and freshwater invertebrates, it remains lacking for most groups of terrestrial invertebrates (Basualdo, 2011).

Malaise traps are widely considered to be the best method for capturing flying insects, particularly parasitoid wasps (Van Achterberg, 2009; Noyes, 1989). As passive flight interception traps, they can be left in the field for long periods and are simple to operate (New, 1998). However, despite their popularity, very little is known about how their number, placement, and sampling duration influence the species diversity of the resulting catch (Fraser et al., 2008). Malaise traps are typically deployed in very low numbers which increases the risk of significantly underestimating total species richness, missing many rare taxa, or biasing the catch due to their placement (Fraser et al., 2007). This can be problematic when few or low numbers of individuals are caught, because the number of individuals captured affects the accuracy of species diversity estimates (Chao \& Chiu, 2016). 
94

95

96

97

98

99

100

101

102

103

104

105

106

107

108

109

110

111

112

113

114

115

116

117

118

119

120

121

122

123

124

125

126

127

128

129

130

131

132

133

134

135

136

137

138

In addition, little is known about how numbers and placement of Malaise traps, and the duration of trap effort, influences the species richness and diversity of observed parasitoid wasps. In one of the few studies to examine sampling effort, Fraser et al. (2008) intensively studied ichneumonid wasps from two sites in the UK. Even when employing 16 Malaise traps per site, and catching large proportions of all UK species (28\%) from a single site, overall the parasitoid community was incompletely sampled. Consequently, whilst using a small number of traps can contribute useful information about the parasitoid community, their use is likely to greatly underestimate total species richness.

The aim of this paper was to investigate how variation in sampling effort (number of traps, duration) within a site affects the observed and estimated species richness of parasitoid wasps (Hymenoptera: Ichneumonidae). Such information will inform sampling strategies to facilitate cost-effective evaluations of parasitoid wasp diversity.

\section{Materials \& Methods}

\section{Study sites}

This study was undertaken within the Waitakere Ranges, located in northern New Zealand. The Waitakere Ranges encompasses 17,000 hectares, ranging from sea level to $474 \mathrm{~m}$, with mean annual temperature from 12.5 to $14.5^{\circ} \mathrm{C}$ and mean annual precipitation between 1400 to $2000 \mathrm{~mm}$ (Jongkind \& Buurman 2006). The vegetation is comprised of a podocarp-broadleaf mixture, with aggregated stands of the endemic conifer, Kauri (Agathis australis).

Two sites within the greater Waitakere Ranges were selected for sampling, Huapai ( $36^{\circ} 47^{\prime} 43.8^{\prime \prime S}$, $\left.174^{\circ} 29^{\prime} 25.5^{\prime \prime E}\right)$ and Oratia $\left(36^{\circ} 55^{\prime} 01.3^{\prime \prime S}, 174^{\circ} 36^{\prime} 12.0^{\prime \prime} \mathrm{E}\right)$. Permission to conduct the study was obtained through the Auckland Council (\#CS57). Both sites are characterised as Kauri forest in various stages of regeneration (Thomas \& Ogden 1983). The mean temperature over the study period was $17.7^{\circ} \mathrm{C}$ (lowest $11.8^{\circ} \mathrm{C}$, highest $25.1^{\circ} \mathrm{C}$ ). Total rainfall was $71 \mathrm{~mm}$.

\section{Sampling}

Twenty Malaise traps were used at each site. Traps were variants of the Townes (1972) style, predominantly the 'ez-Malaise trap' (http://bugdorm.megaview.com). Traps were spaced 20-30m along a central transect that ran approximately through the middle of each site, and some traps were haphazardly placed $20-30 \mathrm{~m}$ either side of the central transect. Where possible, traps were positioned across likely flight paths of insects with the head facing the sun's zenith (Noyes, 1989; Van Achterberg, 2009).

Sampling took place during the austral summer in 2014-2015, and three sampling periods were conducted at each site, each of 1 week duration. Huapai was sampled between 24/11-1/12/2014, $7-14 / 01 / 2015$, and 2-9/02/2015. Oratia was sampled between 2-9/12/2014, 17-24/01/2015, and 1017/02/2015. This gave a total of 420 Malaise-trap-days for each site (20 Malaise traps, 3 sampling periods, and 7 days per trap). Collection bottles were filled with a 50/50 mix of ethanol and glycol. 
139 All Hymenoptera were removed from Malaise trap samples, and stored in 95\% ethanol. 140 Ichneumonidae were sorted to subfamily and genus level. Specimens were identified primarily 141 through an online key to genera (Schnitzler \& Ward, 2013). The New Zealand ichneumonid fauna

142 is relatively poorly known, with most groups requiring extensive species-level revision. For taxa 143 lacking resolution to species level, a morphospecies approach was used. To improve the accuracy 144 of delimitation, morphospecies were compared with specimens within the New Zealand Arthropod 145 Collection. DNA barcoding was utilised to ensure females and males were correctly associated 146 (Supplementary Information 1). All sequences are publicly available on BOLD 147 (http://www.boldsystems.org) under the project "IchneumonidaeDiversityMSc (LKMSC) with 148 Process Id numbers from LKMSC191-16 to LKMSC285-16. All specimens are held at the New 149 Zealand Arthropod Collection, Auckland.

150

151

152

\section{Environmental Factors}

In order to determine the influence of vegetation and environmental variables on Hymenoptera catches, at each trap a circular quadrat of $5 \mathrm{~m}$ diameter was used to measure: (i) the total number of pieces of CWD (with a diameter of at least 7cm); (ii) the number of all plant species present; and (iii) proportional measures of five ground cover types: Kauri debris (Agathis australis); Nikau Palm (Rhopalostylis sapida) debris; coarse woody debris (CWD); other leaf litter; and bare ground.

\section{Data analysis}

Species estimates. A range of species richness indices and estimators were generated from sample-based datasets using EstimateS v9.1.0 (Colwell \& Elsensohn, 2014). Three richness estimators were used based on their accuracy under conditions relevant to the present study (for review see Hortal et al 2006): two incidence-based estimators (ICE and Chao2) and the secondorder 'jackknife' estimator (Jack2). The 'classic formula' was used for calculating Chao2 values as recommended in-software (Colwell \& Elsensohn, 2014). A total of 1000 randomizations were used for each analysis, and the upper abundance limit for rare or infrequent taxa was left at the default of 10. This parameter allows users to specify an upper limit for samples or individuals, below which the species would be classified as 'rare.' This information is used by EstimateS for calculating ACE and ICE (see Chazdon et al., 1997). Sampling efficiency was calculated from Observed species $\left(\mathrm{S}_{\mathrm{obs}}\right) /$ Estimated species $\left(\mathrm{S}_{\mathrm{est}}\right)$.

Sample-based taxon resampling (rarefaction) curves were generated from EstimateS output for each period at each site to show the relationship between sampling effort and observed species richness. Individual-based rarefaction curves were also plotted to provide a comparison of species richness that takes into account the different number of individuals collected from each site (Gotelli \& Colwell, 2001).

Species composition. Similarity-based, multivariate analyses were conducted in PRIMER-E v.6 (Clarke \& Gorley, 2006). Data did not require standardising as identical sampling procedures and effort were maintained over the course of the study. Parasitoid abundance data were square root transformed. Environmental data were normalised by subtracting the mean and dividing by the standard deviation within each variable. Factors were site (Oratia or Huapai); trap type (one of three Townes-style designs used); and sample month (December, January, February). 
185 Resemblance matrices were constructed by applying a zero-adjusted Bray-Curtis coefficient to

186

187

188

189

190

191

192

193

194

195

196

197

198

199

200

201

202

203

204

205

206

207

208

209

210

211

212

213

214

215

216

217

218

219

220

221

222

223

224

225

226

227

228

229

230 parasitoid abundance, and Euclidean distance to environmental data (Clarke \& Gorley, 2006). A zero-adjusted Bray-Curtis coefficient addresses the 'double zero' problem and helps to correct the erratic behaviour of the coefficient when samples become sparse (Clarke et al., 2006). In PRIMERE, zero-adjusting the coefficient is accomplished by adding a 'dummy variable' with values of 1 for each sample (Clarke \& Gorley, 2006). This method was justified because sample sizes were sufficiently large and were taken close enough together in space to assume that samples would have low species richness and abundance for the same reason. For non-metric Multi-Dimensional Scaling (nMDS) ordination, fifty restarts with a minimum stress value of 0.01 were used for each analysis.

Environmental factors. Physical distances between traps were measured (range 20-180m apart) and the similarity of the catch (using Bray-Curtis similarity coefficient) was determined for each pair of traps (20 traps, 190 pairwise combinations) to examine spatial autocorrelation. A BEST test was used to compare environmental variables surrounding a trap with the parasitoid composition and abundance (Clarke \& Gorley, 2006).

\section{Results}

\section{Parasitoid Diversity}

A total sampling effort of 840 Malaise-trap-days at both sites over a period of 3 months resulted in the capture of 61 morphospecies, from 568 individuals. Only 10\% of species were identified to the species level. There was a very strong correlation $(\mathrm{R}=0.934)$ between frequency (number of times sampled) and abundance (number of individuals) of species.

Despite the intensive sampling effort, only 13 species comprised more than 10 individuals, while $40 \%$ of species were singletons $(n=24)$ and $16 \%$ were doubletons $(n=10)$. Each month there was a high ratio of singletons (known from only one sample) to observed species richness (range $34.5 \%$ $73.9 \%$; Table 1). The number of ichneumonids caught was less than 1 per trap per day (all periods; Haupai $=0.91$ per day; Oraita $=0.44$ per day), except Haupai in February (Table 1).

Observed species richness $\left(\mathrm{S}_{\mathrm{obs}}\right)$ peaked in February at both sites (Table 1). A greater number of species and individuals were sampled at the Haupai site, and this was consistent each month. Twenty eight species were found only at the Huapai site (46\%), 14 were exclusive to Oratia (23\%), and 19 were found at both localities (31\%).

\section{Species Accumulation}

Despite the use of twenty traps, observed species richness failed to reach an asymptote at either site (Fig. 1, 2). Sampling efficiency $\left(\mathrm{S}_{\mathrm{obs}} / \mathrm{S}_{\mathrm{est}}\right)$ was only $62.7-66.9 \%$ at Huapai and $36.6-50.3 \%$ at Oratia, depending on the species richness estimator used.

The average proportion of species caught from one trap varied between $7.2-21.2 \%$, and from two traps between $13.2-32.4 \%$, of the total catch from twenty traps (depending on site/period combinations, see Table 2). 
231 Estimates of species richness were often very different depending on the month of sampling (Table 232 2). For example, using the ICE estimator, estimates of species richness at Huapai varied between 233105 species (December), 42 species (January), and 66 species (Feb).

Not surprisingly, more individuals were captured with greater sampling effort, that is, in combinations of 2 or 3 periods. However, examining combinations of different time periods could be useful for planning about specifically when to undertake sampling. For both sites, a combination of January and February resulted in the capture of the highest number of individuals (Figures 3). However, the combination of December and February captured a similar number of species from fewer individuals (Figures 3), indicating the importance of sampling in December (early summer).

\section{Variation of Individual Traps}

Some traps contributed very little to the numbers of overall individuals caught (Table 3). The top 10 traps (i.e. $50 \%$ of traps) caught $81 \%$ of individuals at Huapai and $93 \%$ of individuals at Oratia (Table 3). However, at Oratia $20 \%$ of traps $(n=4)$ failed to catch any ichneumonids over the entire sampling period. Furthermore, one-third of traps at Huapai $(n=7 / 20)$, and two-thirds at Oratia $(n=13 / 20)$ caught less than 10 individuals.

The composition of parasitoids was not affected by site (ANOSIM R $=0.161$, Figure 4A) or month (ANOSIM R = 0.109, Figure 4B). The distances between sets of traps (pairwise distances) did not affect the similarity of the trap catches (using Bray-Curtis similarity coefficient) for either Huapai $($ Rho $=-0.366$, Figure $5 \mathrm{~A})$, or Oratia $(\mathrm{Rho}=-0.338$, Figure $5 \mathrm{~B})$. Furthermore, there was no relationship between environmental factors (vegetation structure, plant diversity, ground cover) immediately surrounding a trap and the composition of parasitoids in the trap (BEST analysis, Rho $=0.18)$.

\section{Discussion}

Our aim of this paper was to investigate how variation in sampling effort affects the observed and estimated species richness of Ichneumonid parasitoid wasps.

We found that even with an intensive Malaise-trapping regime covering a 3-month summer period, at best only two-thirds of parasitoid wasp species were captured (approximately $62-67 \%$ of species were captured at Haupai, but less, 36-50\%, at Oratia). There was also a high degree of variation in estimated number of species depending on the month of sampling and the statistical estimator used. Consequently, the use of only one or two traps would have caught only a small proportion of all species. Furthermore, many traps contributed little to the overall number of individuals caught. Variation in the catch of individual Malaise traps was not explained by seasonal turnover of species, vegetation or environmental conditions surrounding the trap, or the distance of traps to one another.

A number of recent studies have examined the biology of ichneumonid parasitoid wasps and how their diversity relates to such factors as the influence of vegetation structure on life history traits (Saaksjarvi et al 2006); differences between habitat types (Mazon \& Bordera, 2008; Kendall \& Ward 2016); altitudinal gradients (Hall et al 2014); diversity in the tropics and along latitudinal 
277 gradients (Eagalle \& Smith 2017); and spillover of species between natural and managed forests 278 (Frost et al 2015). However, very few studies have examined how numbers and placement of 279 Malaise traps and the duration of trap effort influences the species richness and diversity of 280 parasitoid wasps (Darling \& Packer 1988; Fraser et al. 2008).

281

282

283

284

285

286

287

288

289

290

291

292

293

294

295

296

297

298

299

300

301

302

303

304

305

306

307

308

309

310

311

312

313

314

315

316

317

318

319

320

321

322

Fraser et al. (2008) found that although local parasitoid diversity can be very high from a single site, for example, capturing $28 \%$ of all UK species, even with high sampling effort the overall parasitoid community was still incompletely sampled. They showed how a small number of traps underestimated total species richness, for example, two traps would have caught $32-47 \%$ of the total species (Fraser et al. 2008). Our study confirmed this general finding, but found that two traps would have captured an even lower proportion of species (13-32\%). Furthermore, we showed that individual trap catch was highly variable. Remarkably, $20 \%$ of traps $(n=4)$ at Oratia failed to catch any ichneumonids over the entire sampling period. Additionally, one-third of traps at Huapai, and two-thirds at Oratia caught less than 10 individuals in total.

The failure to reach an asymptote in the accumulation of species is typical of most invertebrate surveys, even those employing intensive sampling effort sustained over long periods of time (Coddington et al., 2009; Longino et al., 2002). The explanation of 'rarity' (e.g. singletons) is one key to understanding how differences in sampling methods and effort affects estimates of species richness (Novotný \& Basset 2000; Longino et al 2002). Excessive numbers of singletons present statistical problems, as non-parametric estimators use the prevalence of rare species in a set of samples to calculate the true number of species in the habitat: as the ratio of singletons to doubletons increases, so do the estimates of species richness (Gotelli \& Colwell, 2001). There was a high degree of variation in estimated number of species depending on the month of sampling and the statistical estimator used. Part of this variation relates to the statistical uncertainty about the range of likely species contained within the samples. When "fewer" samples are present, estimates of richness are often larger, but once there are "sufficient" samples, more accurate estimates of richness are generated, and these are not always the highest estimate. However, all estimators depend on the variability of the samples, and our data contains many samples with zero individuals and few samples with many individuals. The use of statistical estimators has had considerable review (Hortal et al 2006; Colwell \& Elsensohn, 2014), and the three estimators we choose (ICE, Chao2, Jack2) were based on such reviews, and all are commonly employed in ecology.

High numbers of singleton species are especially common in arthropod surveys, and they may result from errors or biases of sampling methodology (Coddington et al., 2009; Novotny \& Basset, 2000). While Malaise traps are extensively used to catch flying insects, and particularly Ichneumonidae (Van Achterberg, 2009; Noyes, 1989), they are only one of several collecting techniques that could be used (New 1998). Understanding whether a species is caught (or not caught) by a specific sampling technique is important to understand their occurrence and abundance in an area. If a species is present but the sampling method and does not catch or 'detect' a species, then this will bias estimates of species richness and rarity. The combined use of different sampling techniques is vital to fully understand species richness and diversity; however, this comes this an added cost of time to collect and process larger numbers of samples.

Longino et al (2002) completed an inventory of ant diversity over 14 years in Costa Rica. Despite their enormous sampling effort, fifty-one species $(12 \%$ of the total) were still singletons (known from only one sample) at the end of the inventory. They were able to show why many species 
323

324

325

326

327

328

329

330

331

332

333

334

335

336

337

338

339

340

341

342

343

344

345

346

347

348

349

350

351

352

353

354

355

356

357 remained singletons because their long-term study provided excellent knowledge of the rarity of the fauna based on geography, methodology, and local and global distributions. In our study the parasitoid community was characterised by a high proportion of singletons (40\%), however, we only utilised one sampling method. More complete inventories of communities are possible if multiple sampling methods and extensive effort are applied (Longino et al. 2002).

An alternative explanation is that some of these singletons are 'tourist' species (Novotny \& Basset, 2000), passing through the study site between patches of resources (e.g. Frost et al 2015). However, the landscapes surrounding the study sites are a mixture of heavily managed agricultural and urban land-use types, and all of the Ichneumonid species caught in this study are endemic (restricted to New Zealand) or native species, and so are likely to be resident within the native study sites, and not passing through from the surrounding modified landscapes. However, a fundamental limitation of our interpretation of overall diversity and rarity is the very poor knowledge of the ichneumonid fauna in New Zealand. There is a basic lack of knowledge regarding host association, habitat preferences, and geographical distribution for the majority of species (Ward 2012; Kendall \& Ward 2016).

\section{Conclusions and Recommendations}

Biodiversity surveys should include some measure of their completeness to contextualise findings and facilitate comparison with other surveys (New, 1998). Quantification of sampling effort in relation to observed species richness is often the first step in developing standardised, cost-effective, optimal sampling regimes (New, 1998).

This study quantified how sampling effort affects the observed and estimated species richness of parasitoid wasps (Hymenoptera: Ichneumonidae) in New Zealand for the first time. Understanding how sampling effort affects the richness and diversity of parasitoid wasps is a useful first step for future studies. Overall the results demonstrate that sampling effort (number of trap used, duration) strongly influences the observed and estimated species richness of parasitoid wasps. Malaise traps work well for the collection of Ichneumonidae, but far more trapping effort is needed; the use of only a few traps and/or for very short periods limits the estimates of richness because i) fewer individuals are caught with a greater number of singletons; and ii) the considerable variation of individual traps means some traps will contribute few or no individuals. 


\section{Acknowledgements}

359

360 We thank those who helped in the field, and staff from Landcare Research and the New Zealand 361 Arthropod Collection for their support and expertise.

362

363 
364

365

366

367

368

369

370

371

372

373

374

375

376

377

378

379

380

381

382

383

384

385

386

387

388

389

390

391

392

393

394

395

396

397

398

399

400

401

402

403

404

405

406

407

408

\section{References}

Chao, A., \& Chiu, C.-H. (2016). Nonparametric estimation and comparison of species richness. In eLS (pp. 1-11). Chichester, UK: John Wiley \& Sons, Ltd. Retrieved from http://doi.wiley.com/10.1002/9780470015902.a0026329

Chapin III, F. S., Zavaleta, E. S., Eviner, V. T., Naylor, R. L., Vitousek, P. M., Reynolds, H. L., Hooper DU, Lavorel S, Sala OE, Hobbie SE, Mack MC, Díaz S. (2000). Consequences of changing biodiversity. Nature, 405(6783), 35012241. https://doi.org/10.1038/35012241

Chazdon RL, Colwell RK, Denslow JS, G uariguata MR (1997). Statistical methods for estimating species richness of woody regeneration in primary and secondary rain forests of NE Costa Rica. In: Dallmeier F, Corniskey J (Eds.), Forest biodiversity in North, Central and South America and the Caribbean: research and monitoring. Paris: Parthenon Publishing, pp 285309.

Clarke, K. R., \& Gorley, R. N. (2006). PRIMER v6: User manual (p. 192pp). Plymouth, UK: PRIMER-E.

Clarke, K. R., Somerfield, P. J., \& Chapman, M. G. (2006). On resemblance measures for ecological studies, including taxonomic dissimilarities and a zero-adjusted Bray-Curtis coefficient for denuded assemblages. Journal of Experimental Marine Biology and Ecology, 330(1), 55-80. https://doi.org/10.1016/j.jembe.2005.12.017

Coddington, J. A., Agnarsson, I., Miller, J. A., Kuntner, M., \& Hormiga, G. (2009). Undersampling bias: the null hypothesis for singleton species in tropical arthropod surveys. Journal of Animal Ecology, 78(3), 573-584. https://doi.org/10.1111/j.1365-2656.2009.01525.x

Colwell, R. K., \& Elsensohn, J. E. (2014). EstimateS turns 20: Statistical estimation of species richness and shared species from samples, with non-parametric extrapolation. Ecography, 37(6), 609-613. https://doi.org/10.1111/ecog.00814

Darling, D. C., \& Packer, L. (1988). Effectiveness of Malaise traps in collecting Hymenoptera: The influence of trap design, mesh size, and location. The Canadian Entomologist, 120(8-9), 787-796. https://doi.org/10.4039/Ent120787-8

Eagalle T, Smith MA. (2017). Diversity of parasitoid and parasitic wasps across a latitudinal gradient: using public DNA records to work within a taxonomic impediment. Facets, 2, 937954.

Eggleton, P., \& Gaston, K. J. (1990). "Parasitoid" species and assemblages: Convenient definitions or misleading compromises? Oikos, 59(3), 417-421. https://doi.org/10.2307/3545155

Fraser, S. E. M., Dytham, C., \& Mayhew, P. J. (2007). Determinants of parasitoid abundance and diversity in woodland habitats. Journal of Applied Ecology, 44(2), 352-361. https://doi.org/10.1111/j.1365-2664.2006.01266.x

Fraser, S. E. M., Dytham, C., \& Mayhew, P. J. (2008). The effectiveness and optimal use of Malaise traps for monitoring parasitoid wasps. Insect Conservation and Diversity, 1(1), 2231. https://doi.org/10.1111/j.1752-4598.2007.00003.x

Frost CM, Didham RK, Rand TA, Peralta G, Tylianakis JM. 2015. Community-level net spillover of natural enemies from managed to natural forest. Ecology 96(1): 193-202.

Gaston, K.J. 1991. The magnitude of global insect species richness. Conservation Biology 5(3), 283-296.

Gotelli, N. J., \& Colwell, R. K. (2001). Quantifying biodiversity: Procedures and pitfalls in the measurement and comparison of species richness. Ecology Letters, 4(4), 379-391. 
441

442

443

444

445

446

447

448

449

450

451

452

453

454

Hall CR, Burwell CJ, Nakamura A, Kitching RL. 2015. Altitudinal variation of parasitic Hymenoptera assemblages in Australian subtropical rainforest. Austral Entomology. 54: 246-258.

Holwell, G. I., \& Andrew, N. I. (2014). Protecting the small majority: Insect conservation in Australia and New Zealand. In A. Stow, N. Maclean, \& G. I. Holwell (Eds.), Austral Ark: The State of Wildlife in Australia and New Zealand. Cambridge: Cambridge University Press.

Hortal, J., Borges, P. a. V., \& Gaspar, C. (2006). Evaluating the performance of species richness estimators: Sensitivity to sample grain size. Journal of Animal Ecology, 75(1), 274-287. https://doi.org/10.1111/j.1365-2656.2006.01048.x

Jongkind, A. G., \& Buurman, P. (2006). The effect of kauri (Agathis australis) on grain size distribution and clay mineralogy of andesitic soils in the Waitakere Ranges, New Zealand. Geoderma, 134(1), 171-186. https://doi.org/10.1016/j.geoderma.2005.10.004

Keating, K. A., Quinn, J. F., Ivie, M. A., \& Ivie, L. L. (1998). Estimating the effectiveness of further sampling in species inventories. Ecological Applications, 8(4), 1239-1249.

Kendall L, \& Ward DF. (2016). Habitat determinants of the taxonomic and functional diversity of parasitoid wasps. Biodiversity \& Conservation, 25(10), 1955-1972.

Longino, J. T., Coddington, J., \& Colwell, R. K. (2002). The ant fauna of a tropical rain forest: Estimating species richness three different ways. Ecology, 83(3), 689-702.

Mazon, M., \& Bordera, S. (2008). Effectiveness of two sampling methods used for collecting Ichneumonidae (Hymenoptera) in the Cabaneros National Park (Spain). European Journal of Entomology, 105(5), 879-888.

Mora, C., Tittensor, D. P., Adl, S., Simpson, A. G. B., \& Worm, B. (2011). How Many Species Are There on Earth and in the Ocean? PLOS Biology, 9(8), e1001127.

New, TR. (1998). Invertebrate surveys for conservation. Oxford, NY: Oxford University Press.

New TR. (2009). Insect Species Conservation. Cambridge University Press.

New, T. R. (2012). Hymenoptera and conservation. Hoboken, NJ: Wiley-Blackwell.

Novotný, V., \& Basset, Y. (2000). Rare species in communities of tropical insect herbivores: pondering the mystery of singletons. Oikos, 89(3), 564-572.

Noyes, J. S. (1989). A study of five methods of sampling Hymenoptera (Insecta) in a tropical rainforest, with special reference to the Parasitica. Journal of Natural History, 23(2), 285298.

Potts, S. G., Biesmeijer, J. C., Kremen, C., Neumann, P., Schweiger, O., \& Kunin, W. E. (2010). Global pollinator declines: Trends, impacts and drivers. Trends in Ecology \& Evolution, 25(6), 345-353.

Saaksjarvi IE, Ruokolainen K, Tuomisto H, Haataja S, Fine PVA, Cardenas G, Mesones I, Vargas V. Comparing composition and diversity of parasitoid wasps and plants in an Amazonian rain-forest mosaic. 2006. Journal of Tropical Ecology. 22: 167 - 176.

Samways MJ. 2005. Insect Diversity Conservation. Cambridge University Press.

Schnitzler, F.-R., \& Ward, D. F. (2013). Key to Ichneumonidae in New Zealand. Retrieved November 8, 2016, from https://www.landcareresearch.co.nz/resources/identification/animals/ichneumonidae

Sluys, R. (2013). The unappreciated, fundamentally analytical nature of taxonomy and the implications for the inventory of biodiversity. Biodiversity and Conservation, 22(4), 10951105.

Thomas, G. M., \& Ogden, J. (1983). The scientific reserves of Auckland University I. General introduction to their history, vegetation, climate and soils. Tane, 29, 143-162. 
455 Townes, H. (1972). A light-weight Malaise trap. Entomological News, 83, 239-247.

456 Van Achterberg, C. (2009). Can Townes type Malaise traps be improved? Some recent 457 developments. Entomologische Berichten, 69, 129-135.

458 Van Driesche, R. G., Carruthers, R. I., Center, T., Hoddle, M. S., Hough-Goldstein, J., Morin, L., 459 van Klinken, R. D. (2010). Classical biological control for the protection of natural 460 ecosystems. Biological Control, 54, S2-S33.

461 Ward, D. F. (2012). More Than Just Records: Analysing Natural History Collections for $462 \quad$ Biodiversity Planning. PLOS ONE, 7(11), e50346.

463 Ward, D. F., Early, J. W., Schnitzler, F.-R., Hitchmough, R. A., \& Stringer, I. A. N. (2012). The 464 conservation status of New Zealand Hymenoptera. New Zealand Entomologist, 35(2), 116$465 \quad 119$.

466 Wheeler, Q. D., Knapp, S., Stevenson, D. W., Stevenson, J., Blum, S. D., Boom, B. M., ... 467 Woolley, J. B. (2012). Mapping the biosphere: exploring species to understand the origin, 468 469 organization and sustainability of biodiversity. Systematics and Biodiversity, 10(1), 1-20.

470 


\section{Table $\mathbf{1}$ (on next page)}

Summary of Malaise trap catches of Ichneumonidae from Huapai and Oratia sites across the sampling periods (December, January, February, and combined).

Number of individuals; number of species caught $\left(\mathrm{S}_{\text {obs }}\right)$; number of singletons; number of doubletons; and the ratio of singletons $/ \mathrm{S}_{\text {obs }}$. 
1

2 Table 1. Summary of Malaise trap catches of Ichneumonidae from Huapai and Oratia sites 3 across the sampling periods (December, January, February, and combined). Number of 4 individuals; number of species caught $\left(\mathrm{S}_{\mathrm{obs}}\right)$; number of singletons; number of doubletons; and the 5 ratio of singletons $/ \mathrm{S}_{\mathrm{obs}}$.

6

\begin{tabular}{|l|l|l|l|l|l|}
\hline $\begin{array}{l}\text { Site / Period } \\
\text { trap days) }\end{array}$ & Individuals & $\begin{array}{l}\text { Observed } \\
\text { Species } \mathbf{( S}_{\mathbf{0 b s}} \text { ) }\end{array}$ & Singletons & Doubletons & $\begin{array}{l}\text { Singletons } \\
\mathbf{~ S}_{\mathbf{o b s}} \mathbf{\%}\end{array}$ \\
\hline Huapai & & & & & \\
\hline December (140) & 60 & 23 & 17 & 1 & 73.9 \\
\hline January (140) & 113 & 29 & 10 & 5 & 34.5 \\
\hline February (140) & 210 & 35 & 18 & 1 & 51.4 \\
\hline Combined (420) & 383 & 49 & 18 & 7 & 36.7 \\
\hline Oratia & & & & & \\
\hline December (140) & 33 & 13 & 8 & 2 & 61.5 \\
\hline January (140) & 88 & 18 & 12 & 0 & 66.7 \\
\hline February (140) & 64 & 20 & 12 & 3 & 60.0 \\
\hline Combined (420) & 185 & 33 & 19 & 1 & 57.6 \\
\hline Total (840) & 568 & 61 & 24 & 10 & 39.3 \\
\hline
\end{tabular}

8 


\section{Table 2 (on next page)}

Estimated species richness of Ichneumonidae from Malaise trap catches at Huapai and Oratia sites across the sampling periods (December, January, February, and combined) using three estimators (ICE, Jack2, and Chao2).

Proportions of species caught from 1 trap and 2 traps (as a \% from a total of twenty traps). 
1

2 Table 2. Estimated species richness of Ichneumonidae from Malaise trap catches at Huapai 3 and Oratia sites across the sampling periods (December, January, February, and

4 combined) using three estimators (ICE, Jack2, and Chao2). Proportions of species caught

5 from 1 trap and 2 traps (as a \% from a total of twenty traps).

6

\begin{tabular}{|l|l|l|l|l|l|}
\hline Site/ Period & ICE & Jack2 & Chao2 & 1 Trap\% & 2 Traps\% \\
\hline Huapai & & & & & \\
\hline December & 105.8 & 55.4 & 176.9 & 8.6 & 16.3 \\
\hline January & 42.8 & 46.0 & 40.4 & 14.0 & 24.6 \\
\hline February & 66.7 & 67.4 & 188.9 & 18.3 & 30.0 \\
\hline Combined & 73.2 & 78.1 & 73.5 & 21.2 & 32.4 \\
\hline Oratia & & & & & \\
\hline December & 27.8 & 27.0 & 25.8 & 7.2 & 13.2 \\
\hline January & 45.2 & 39.3 & 86.4 & 11.4 & 20.6 \\
\hline February & 62.5 & 43.3 & 51.0 & 9.4 & 17.7 \\
\hline Combined & 71.4 & 65.5 & 90.1 & 11.9 & 21.0 \\
\hline Total & 93.9 & 98.7 & 90.6 & 19.7 & 31.0 \\
\hline
\end{tabular}

7

8

9 


\section{Table 3 (on next page)}

Variation in the catches of Ichneumonidae from all periods of summer using Malaise traps at Huapai and Oratia. 
1

2 Table 3. Variation in the catches of Ichneumonidae from all periods of summer using

3 Malaise traps at Huapai and Oratia.

4

\begin{tabular}{|l|l|l|l|l|}
\hline & $\begin{array}{l}\text { Number } \\
\text { traps with } \\
\text { no catch }\end{array}$ & $\begin{array}{l}\text { Number } \\
\text { traps with } \\
\mathbf{1 0} \text { or less } \\
\text { individuals }\end{array}$ & $\begin{array}{l}\text { Number of } \\
\text { individuals } \\
\text { (\%) of top 5 } \\
\text { traps }\end{array}$ & $\begin{array}{l}\text { Number of } \\
\text { individuals } \\
\text { (\%) of top } \\
\mathbf{1 0} \text { traps }\end{array}$ \\
\hline Huapai & 0 & 7 & $191(50 \%)$ & $312(81 \%)$ \\
\hline Oratia & 4 & 13 & $127(69 \%)$ & $172(93 \%)$ \\
\hline
\end{tabular}

5

6 
Figure 1

Species accumulation curves at Huapai for each sampling period.

A. December; B. January; C. February; D. Combined periods, comparing observed species richness (solid line) with three non-parametric estimators of total species richness (ICE squares; Jack2 - triangles; Chao2 - circles).

Figure 2

Species accumulation curves at Oratia for each sampling period.

A. December; B. January; C. February; D. Combined periods, comparing observed species richness (solid line) with three non-parametric estimators of total species richness (ICE squares; Jack2 - triangles; Chao2 - circles).
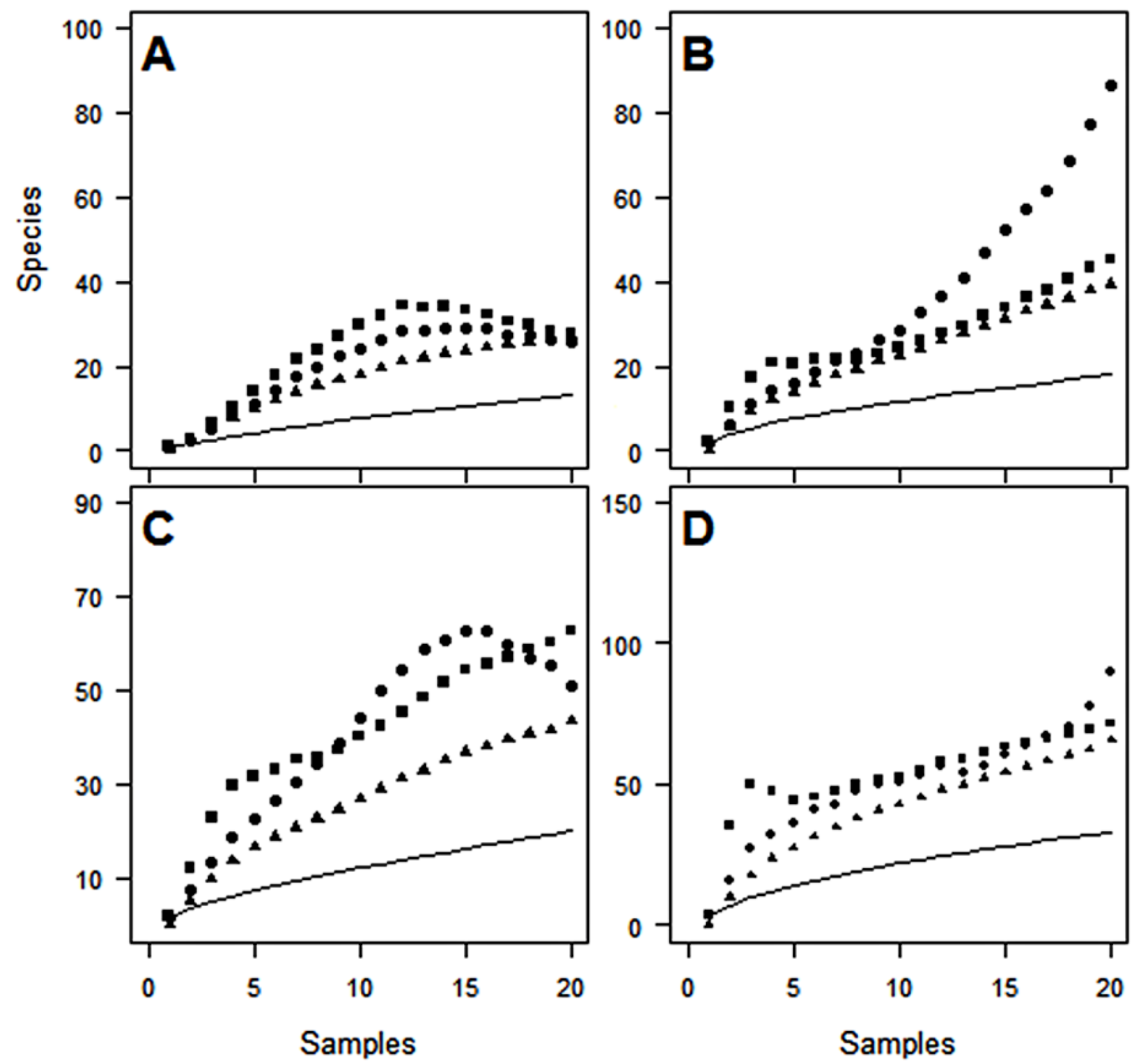
Figure 3

Observed species richness for individual-based rarefaction curves for Huapai (A) and Oratia (B) for different sampling periods.

December (red); January (green); February (dark blue); December+January (dark red); December+February (light blue); January+ February (purple); All periods (black).
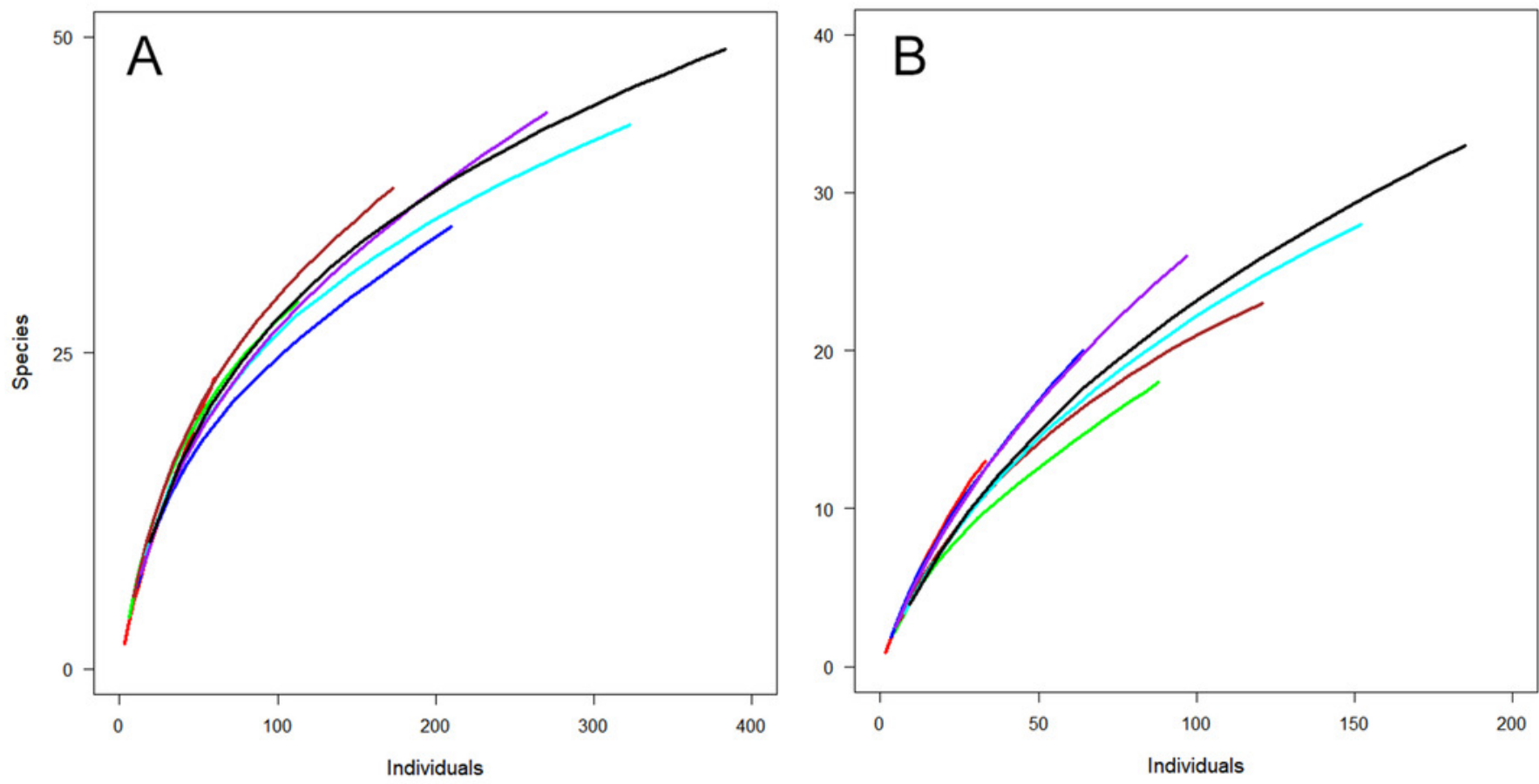


\section{Figure 4}

nMDS plots showing similarity of parasitoid assemblages.

Huapai (A) and Oratia (B) at different sampling periods: December (red triangle), January (yellow circle), and February (green square). 


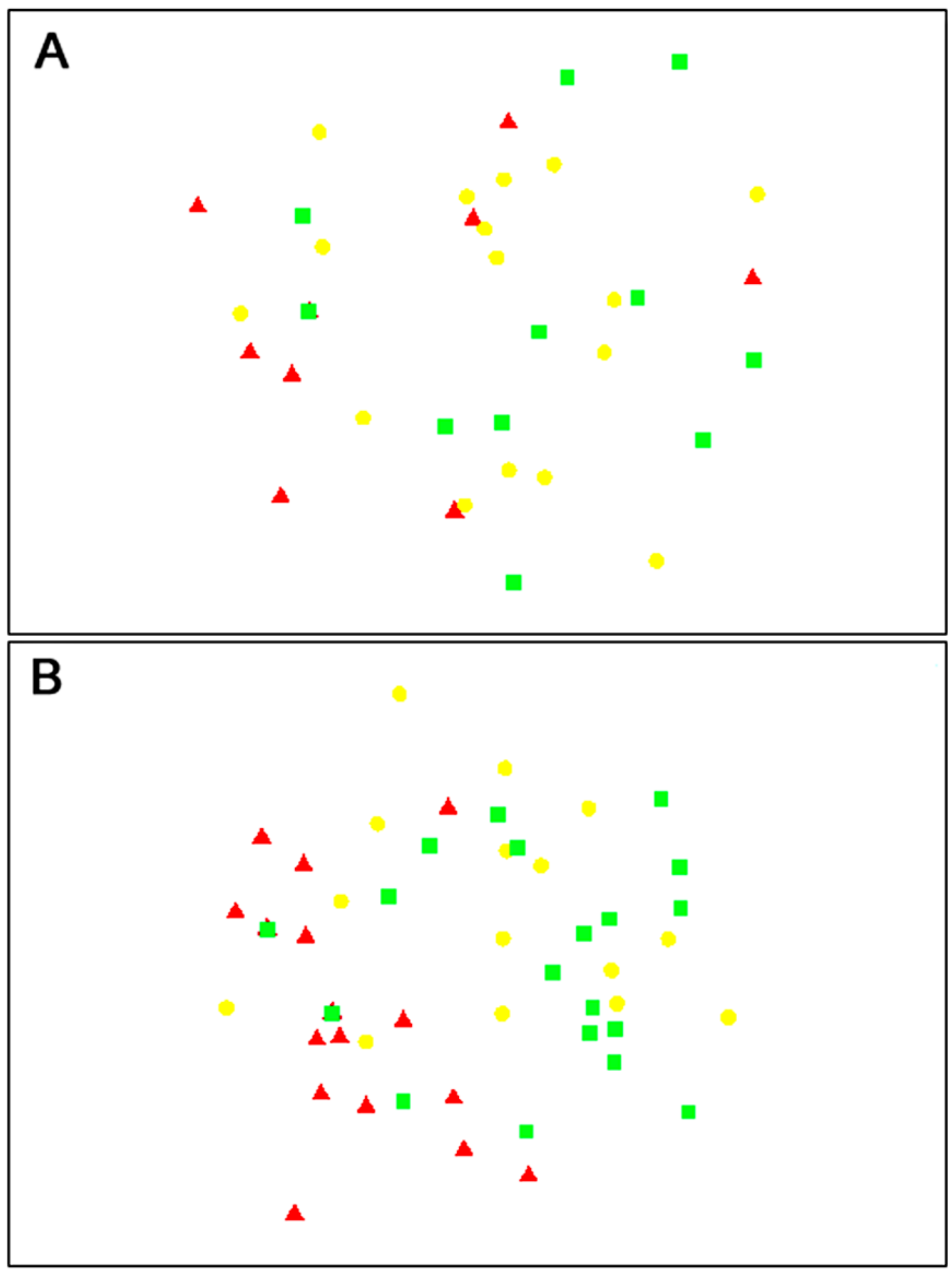


Figure 5

Similarity of trap catches (Bray-Curtis similarity coefficient) against the distance between each trap combinations.

Huapai (A) and Oratia (B). 




